\title{
Environmental Stability of Poly(Vinyl Chloride) Modified by Schiff's Base under Exposure to UV
}

\author{
Ahmed Ahmed 1(i), Mustafa Abdallh 2 (i), Mohammed H. Al-Mashhadani ${ }^{2}$ (D), Dina S. Ahmed ${ }^{3}$ (i), Muna \\ Bufaroosha $^{4}$ (D), Ali H. Jawad ${ }^{5}$ (D), Emad Yousif 2 , *(D) \\ 1 Polymer Research Unit, College of Science, Al-Mustansiriyah University, Baghdad 10052, Iraq; drahmed625@gmail.com \\ (A.A.); \\ 2 Department of Chemistry, College of Science, Al-Nahrain University, Baghdad, Iraq; msar83@gmail.com; \\ Mohammed.mashhadani@ced.nahrainuniv.edu.iq (M.H.); \\ 3 Department of Medical Instrumentation Engineering, Al-Mansour University College, Baghdad, Iraq; \\ dina.saadi@muc.edu.iq (D.S.); \\ 4 Department of Chemistry, College of Science, UAE University, Al-Ain, UAE; muna.bufaroosha@uaeu.ac.ae (M.B.); \\ 5 Faculty of Applied Sciences, Universiti Teknologi MARA, Shah Alam 40450, Selangor, Malaysia; ali288@uitm.edu.my \\ (A.H.J.); \\ * Correspondence: emad_yousif@hotmail.com;
}

Scopus Author ID 26533612800

Received: 11.01.2021; Revised: 5.02.2021; Accepted: 7.02.2021; Published: 13.02.2021

\begin{abstract}
Polymers are used in different applications that might be an issue for the environment. Thus, our strategy is to create a material that can be more sustainable and last longer in use. For this purpose, a new Schiff base was synthesized containing a triazole ring (L), which was introduced to a poly (vinyl chloride) (PVC) chain via substitution reaction. Copper chloride was then added to the previous compound to give the final product PVC-L-Cu. The films' resistivity to degradation under Ultraviolet (UV) light irradiation was investigated under accelerated conditions. Fourier-transform infrared (FTIR) spectroscopy, weight loss, and scanning electron microscopy (SEM) were used to follow the changes after exposure to UV light. The novel Schiff base enhanced the photostability of PVC polymer significantly in comparison to the pristine polymer.
\end{abstract}

Keywords: Schiff base; polystyrene; UV radiation; weight loss; films.

(C) 2021 by the authors. This article is an open-access article distributed under the terms and conditions of the Creative Commons Attribution (CC BY) license (https://creativecommons.org/licenses/by/4.0/).

\section{Introduction}

Plastic has a great impact on our environment. They are used in different applications ranging from domestic, construction to high tech appliances [1,2]. The disposal of these materials can cause serious damage to our environment. However, there is no alternate, or the alternative is very expensive to make it hard to replace with other materials. Therefore, this problem could be solved by creating more sustainable materials that last longer under working conditions [3-5]. PVC, in particular, is a very important polymer in terms of industrial applications. It has been a part of many industries such as pipes, construction, medical appliance, doors, windows shutters, furniture, etc. One of the drawbacks of PVC is that suffering from degradation under UV light, which affects its performance under working conditions [6-10]. For this reason, PVC is mixed with other materials to enhance its performance and increases its lifetime. Although some additives to polymers could represent a solution, sometimes these additives can leak out to the surrounding causing other problems [11-13]. Thus, a recent approach to reduce the leach of additives is by modifying the polymer, which can serve in the same manner as additives in enhancing mechanical properties, 
increasing flexibility, flame retardancy, and UV stability [14-18]. Different materials were used in polymers modification, such as aromatic compounds, phosphines, and metal complexes [1926]. Shafket et al. [27] have used $\mathrm{ZnO}$ to improve and photo stabilizer the polymer used in solar cells. Also, nickel chelate compounds and ligands containing Sulphur are reported to work as hydroperoxide decomposers for polymers to eliminate the formation of radicals [28]. Alaa et al. have reported the use of tin-valsartan complexes with PVC in order to increase the lifetime and stability of PVC [24]. $\mathrm{TiO}_{2}$ was used with PVC to reduce the degradation when exposed to UV light and scatter visible light and protect the polymer's color [29]. In this work, the newly synthesized Schiff base component was introduced PVC polymer and finally coordinated with $\mathrm{CuCl}_{2}$. The photostability and weight loss of the modified PVC were investigated under accelerated exposure conditions to UV light. The morphological changes were also examined via the SEM technique.

\section{Materials and Methods}

\subsection{Materials.}

3,4-dihydroxycyclohexa-1,3-dienecarbaldehyde, carbon disulfide, hydrazine hydrate, Ethyl cyanoacetate, ethanol, and methanol are purchased from Sigma-Aldrich, USA. Polyvinyl chloride is purchased from Korea. All chemicals used in this work are used directly without further purification.

\subsection{Characterization.}

FTIR spectra were measured using Jasco FTIR-4200 spectrophotometer in Tokyo, Japan. The effect of the weather was conducted using QUV Acceleration weather-meter tester supplied by Q-band company, USA. Morphological changes were examined via Inspect S50 microscope provided by FEI Company, Czech Republic.

\subsection{Synthesis of cyanoacetic hydrazide (2).}

In cold methanolic solution, 0.01 mole of ethyl cyanoacetate was dissolved and add to 0.01 mole of hydrazine hydrate in a dropwise manner. The resulted reaction mixture was left overnight to stir at ambient temperature. The precipitate was then collected by filtration and purified by recrystallization in ethyl alcohol to produce 2 [26].

\subsection{Synthesis 3-(acetonitrile)-4-amino-5-mercapto-1,2,4-triazole (3).}

The produced compound $2(0.02 \mathrm{~mol})$ is dissolved in ethanol $(20-25 \mathrm{~mL})$ in the presence of the equivalent amount of $0.02 \mathrm{~mol}$ of $\mathrm{KOH}$. Followed by adding $6 \mathrm{~mL}$ of CS2 to the reaction mixture; after stirring for $15 \mathrm{~min}$. the reaction mixture was stirred continuously until the hydrogen sulfide gas was liberated. After that, $5 \mathrm{~mL}$ of absolute ethanol was added to the reaction mixture, followed by the filtration of the produced solid and washed with ether. The resulted powder was dried under vacuum for $24 \mathrm{~h} .5 \mathrm{~mL}$ of hydrazine hydrate $(80 \%)$ was added to potassium xanthate produced in the previous step to give a suspension then refluxed until a homogeneous solution was formed. Coldwater was added to the filtrate. After acidifying the solution with concentrated $\mathrm{HCl}$, the product was collected, followed by recrystallization from ethanol to get a pure product of 3 [30]. 
2.5. Synthesis (E)-2-(4-((3,4-dihydroxybenzylidene)amino)-5-mercapto-4H-1,2,4-triazol-3yl)acetonitrile (4).

$0.1 \mathrm{~g}$ of compound 3 is mixed with 3,4-dihydroxycyclohexa-1,3-dienecarbaldehyde in a stoichiometric amount in ethanol, followed by the addition of glacial $\mathrm{AcOH}$ to reaction composition. The system was refluxed for 6 hours. The resulted orange precipitate was collected and washed with ethanol and further purified by recrystallization from ethanol to give compound 4.

\subsection{Modification of PVC with compound 4.}

The Schiff base 4 (0.05 g) was dissolved in THF and then added to $0.25 \mathrm{~g}$ of PVC. A few drops of pyridine were added to the previous mixture, then refluxed for $3 \mathrm{~h}$. A new modified PVC was cast onto a glass slide mold to produce a film. The film was set for $24 \mathrm{~h}$ on the mold at room temperature to let the solvent evaporate. The films were of $40 \mu \mathrm{m}$ as a thickness.

\subsection{Preparation of PVC-ligand-Cu(II) complex films.}

$0.6 \mathrm{~g}$ of the freshly modified PVC was dissolved in a minimum amount of THF. $0.1 \mathrm{~g}$ of copper chloride was added and reflux for $3 \mathrm{~h}$. The final product, PVC-L-Cu, was cast on a glass slide. The film was left at ambient temperature to give a homogenous film.

\subsection{Exposure to UV light.}

The prepared films of pure and modified PVC samples were exposed to UV light (QUV tester with $\lambda_{\max }$ set at $313 \mathrm{~nm}$ was used in exposure experiments), the light intensity was fixed at $6.43 \times 10^{-9} \mathrm{ein} \cdot \mathrm{dm}^{-3} \cdot \mathrm{s}^{-1}$. All samples are exposed for different time intervals up to $300 \mathrm{~h}$.

\section{Results and Discussion}

The synthesis of the active compound 4 is shown in Scheme 1. In the first reaction of 1 with hydrazine hydrate in a cooled methanolic solution to give a white powder of 2 with a yield of $56 \%$
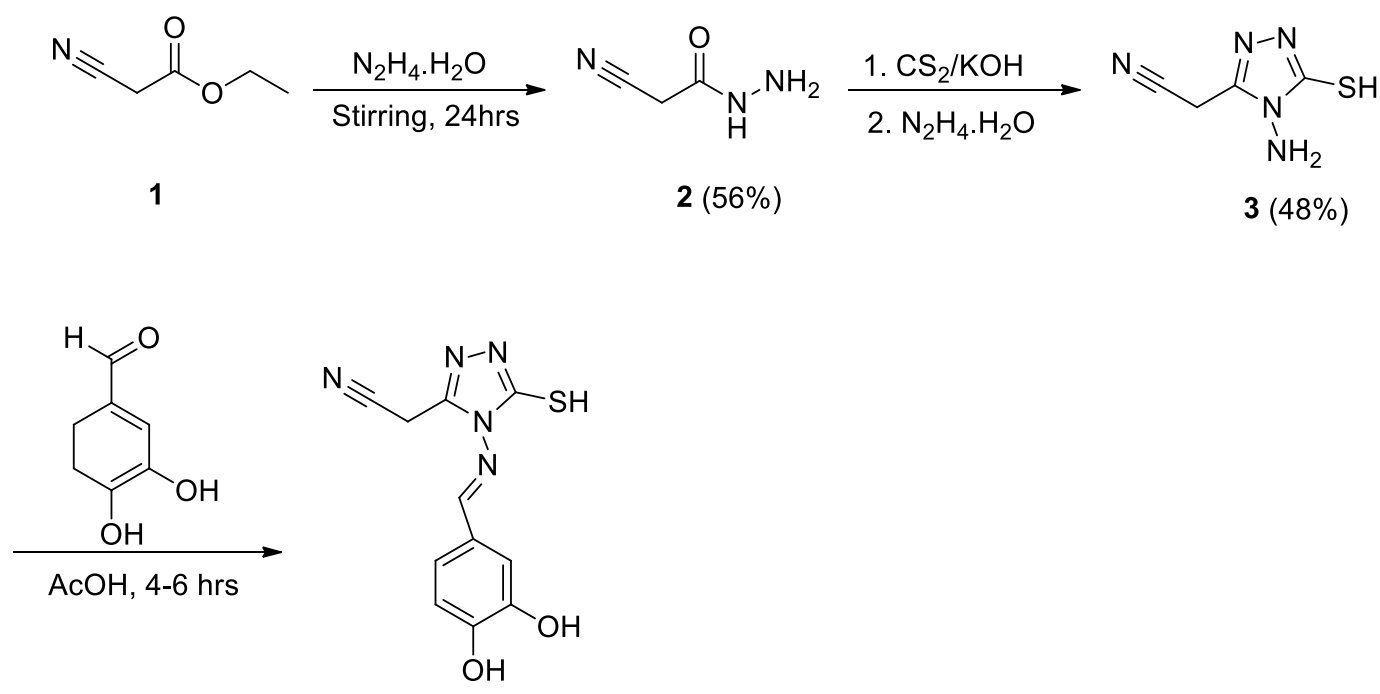

$4(60 \%)$

Scheme 1. Schematic diagram on the synthesis route of compound 4. 
And the melting point of $108-109{ }^{\circ} \mathrm{C}$. The structure was characterized by FTIR spectroscopy via Jasco FTIR-4200 Spectrophotometer at $400-4000 \mathrm{~cm}^{-1}$ ( $\mathrm{KBr}$ disc). Some significant absorption is used to confirm the structure of 2, 3340-3183, and $3112 \mathrm{~cm}^{-1}$ stretching's are attribute to $\mathrm{NH}_{2}$ and $\mathrm{NH}$, respectively. The absorption band at 2980-2936 and $1681 \mathrm{~cm}-1$ correspond to $\mathrm{CH}$ and $\mathrm{C}=\mathrm{O}$, respectively. The second step is to produce the Schiff base compound via the reaction of 2 with hydrazine. A white powder appears in $48 \%$ yield with a decomposition temperature of $307{ }^{\circ} \mathrm{C}$. FTIR absorption frequencies at $3233-3108 \mathrm{~cm}^{-1}$ due to $\mathrm{NH}_{2}$ Stretching. The FTIR spectra show the appearance of a new absorption band at 1586 and $789 \mathrm{~cm}^{-1}$ attributed to the $\mathrm{C}=\mathrm{N}$ and $\mathrm{C}-\mathrm{S}$ groups, respectively. Also, it confirms the disappearance of the $\mathrm{NH}$ band due to the formation of the Schiff base. The last reaction includes the attachment of 3,4-dihydroxycyclohexa-1,3-dienecarbaldehyde to compound 3 in the presence of glacial acetic acid as a catalyst under reflux for $6 \mathrm{~h}$. the final product 4 was collected as an orange precipitate in a yield of $60 \%$ with a melting point of $190-191^{\circ} \mathrm{C}$. From FTIR spectra, it is clear that the $\mathrm{NH}_{2}$ absorption band has vanished completely in addition to the appearance of new absorption bands at 3102, 2844-2921, and $1503 \mathrm{~cm}^{-1}$ attributed to C-H (arom), C-H (ali), and carbon double bond of the newly introduced aromatic ring to the Schiff base structure.

Polymers having a side group capable of undergoing a substitution reaction provide a suitable platform to alter the original properties of the polymer towards more desirable characteristics to be used in a different application or in a sustainable manner. Scientists exploit this feature in PVC to modify it by introducing anchoring aromatic or heterocyclic units via chlorine's displacement reaction [23]. The substation reaction of the facial chlorine atom on the PVC chain occurs via SN2 mechanism. The suggested structure of the modified PVC is presented in figure 1. The modification of the PVC was confirmed by FTIR. For PVC-L, a number of significant absorption bands appear at 2915 and $1413 \mathrm{~cm}^{-1}$ attributed to $(\mathrm{C}-\mathrm{H})$ stretching and $(\mathrm{C}-\mathrm{H})$ bending of $-\mathrm{CH} 2-$, respectively. $621 \mathrm{~cm}^{-1}$ due to $(\mathrm{C}-\mathrm{Cl})$ stretching and stretching vibration at $1581 \mathrm{~cm}^{-1}$ corresponding to $(\mathrm{CH}=\mathrm{N})$.

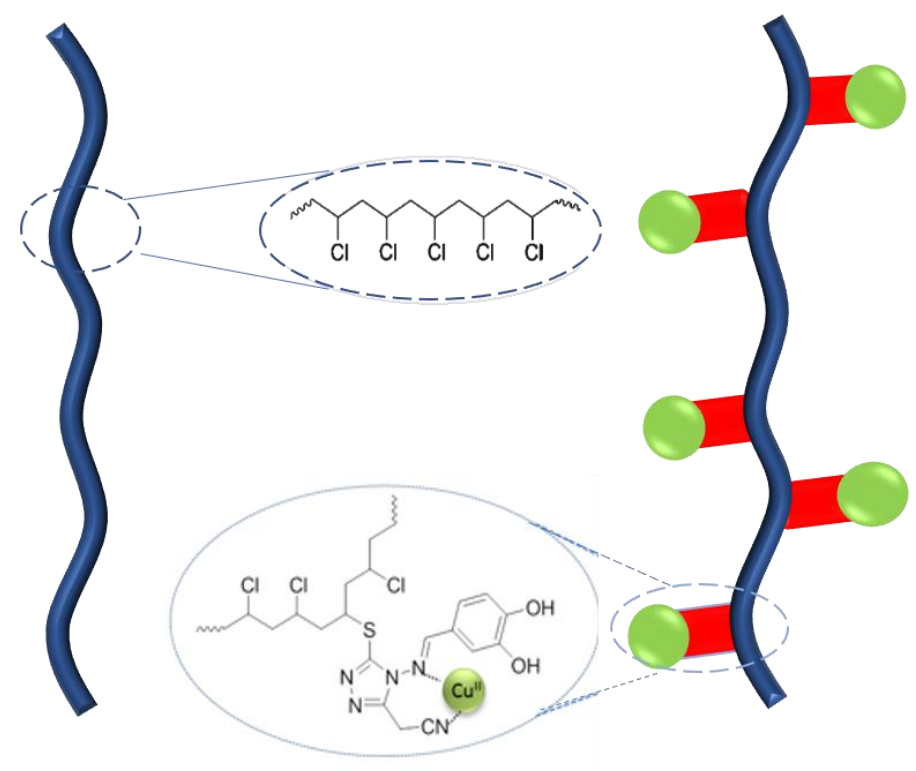

Figure 1. Schematic illustration of the PVC modification. 


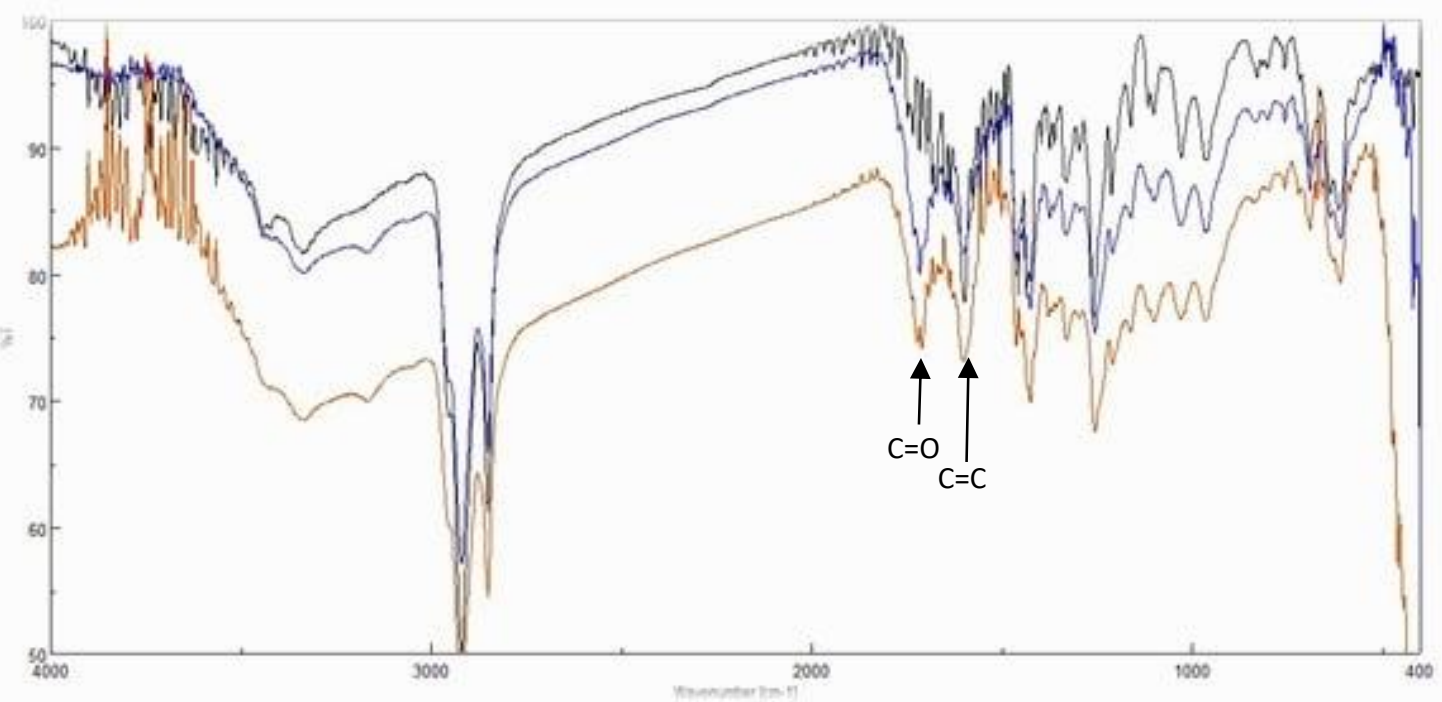

Figure 2 FTIR spectra before and after exposure to UV light (top, 0h; middle. 100h and bottom 300h).

The degradation of PVC upon exposure to UV light usually lead to produce small fragments. Commonly, these fragments are oxygenated compounds of Chloroketones, aldehydes, and chlorocarboxyic acid. FTIR spectroscopy is used in the detection of the carbonyl functional group in the resulted compounds. Thus, FTIR technique quantifies the original and modified PVC polymers' changes after being exposed to UV light for different time intervals. The FTIR spectra were recorded from 0 to $300 \mathrm{~h}$ of UV light exposure. The changes in absorption of the corresponding carbonyl group appear at $1719 \mathrm{~cm}^{-1}$ in which the absorption intensity increased with increasing time of exposure. The FTIR spectra of the final modified polymer (PVC-L-CuII) is illustrated in figure 2 . The frequency at $1330 \mathrm{~cm}^{-1}$ attributed to the $\mathrm{CH}$ group in the PVC structure was used as an internal standard to compare the results with the newly appeared peak of the carbonyl compounds resulting from the degradation process. The carbonyl index $\left(I_{\mathrm{C}=\mathrm{O}}\right)$ was calculated using the following equation:

$$
I_{\mathrm{C}=\mathrm{O}}=\frac{A_{\mathrm{C}=O}}{A_{\text {Ref }}}
$$

Where the $A_{C=O}$ represents the area of the carbonyl group and $A_{\text {Ref }}$ represents the area of the internal standard $\left(\mathrm{CH}\right.$ bond, at $\left.1330 \mathrm{~cm}^{-1}\right)$.

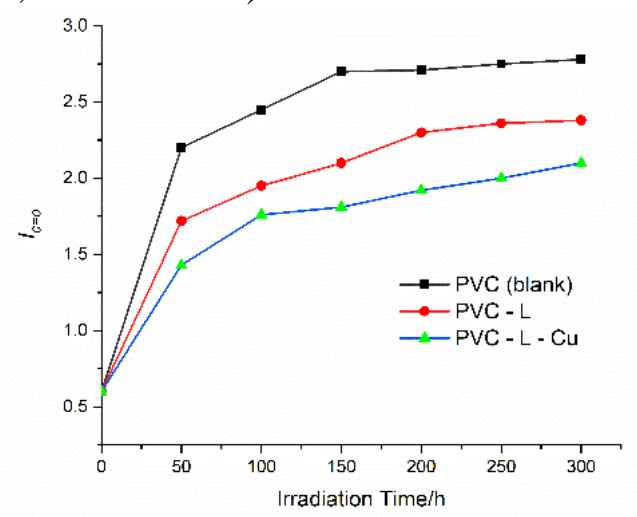

Figure 3. Carbonyl index under exposure to UV light.

The PVC-L-Cu film demonstrates higher resistance to UV degradation than PVC and PVC-L due to the extra stabilization effect obtained by the ligand itself and the copper complex. The photo stabilization effect of the PVC film after irradiation is shown in figure 3. 


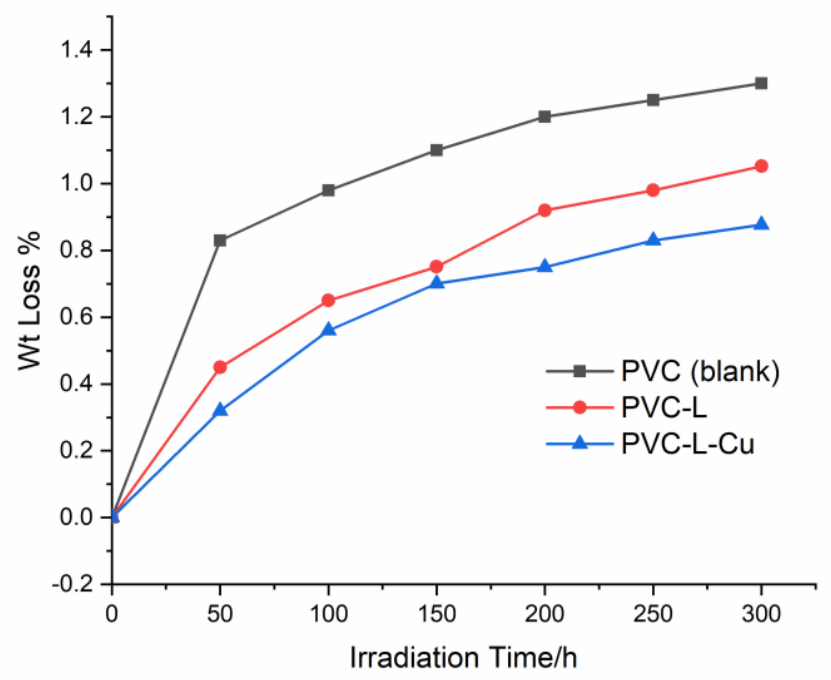

Figure 4. Percentage change of pure and modified PVC films after exposure to UV light.

The previous experiment suggested that exposure to UV light can cause degradation of PVC polymer in the form of compounds containing the carbonyl group. These results were further investigated by measuring the differences in the specimens' weight before irradiation and after being exposed to UV light. The samples were exposed to UV light under accelerated conditions at a different time interval for a total of $300 \mathrm{~h}$. Analytical balance was used to measure the weight differences. The data were illustrated in figure 4. The obtained results revealed that weight loss in polymer samples, especially pristine PVC samples, has suffered a higher loss than modified polymers. These results showed that PVC modification enhances the PVC films' photostability, where less weight loss was recorded with PVC-L-Cu sample. These data are well agreed with the FTIR experiment data, which proves that our system is working very well in reducing the polymer's degradability under UV irradiation [31].

The morphology of pure PVC film exhibits a flat and uniform surface, as shown in figure 5. On the other hand, PVC-L-Cu polymer demonstrates a porous surface after exposure to UV light, as shown in figures 6,7. Such fabrication may contribute to forming a crosslinked network resulting from the coordination of $\mathrm{Cu}$ on one of the polymer chains with an adjacent ligand on another chain. In addition to the release, $\mathrm{HCl}$ gas resulted from the degradation process and other vaporous compounds [32].

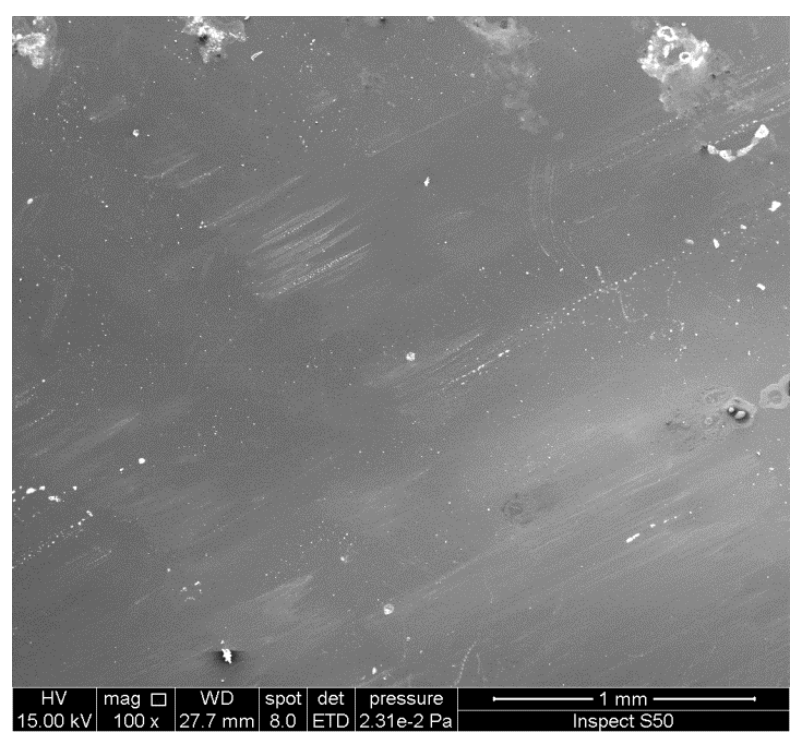

Figure 5. Pristine PVC under SEM. 


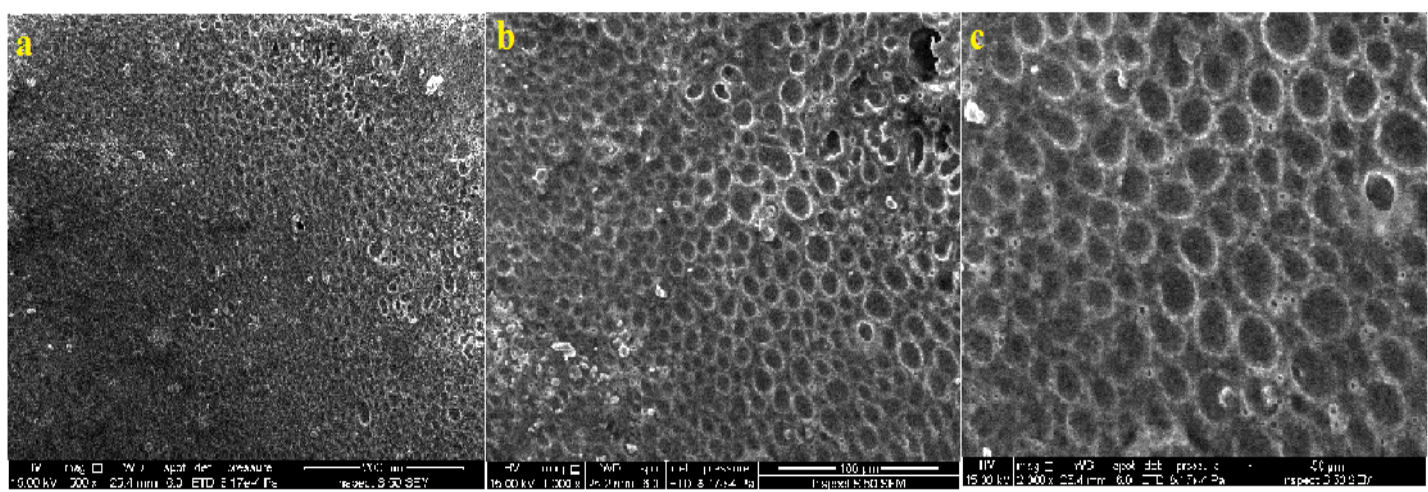

Figure 6. Surface morphology of PVC-L-Cu under SEM after $300 \mathrm{~h}$ exposure to UV light (a) $200 \mu \mathrm{m}$; (b) 100 $\mu \mathrm{m}$ and (c) $50 \mu \mathrm{m}$ scale.

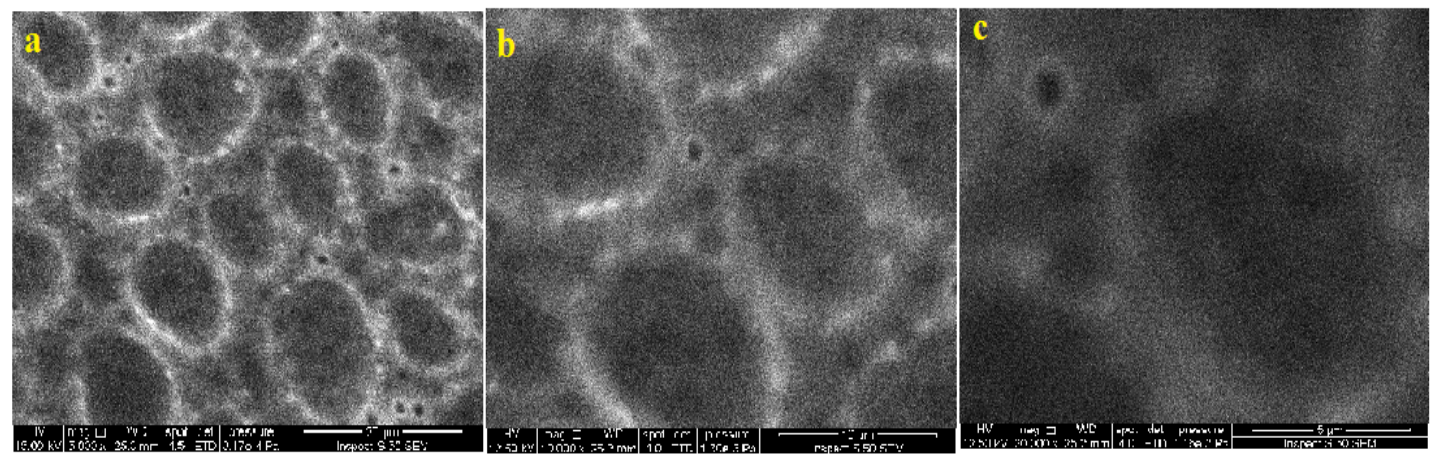

Figure 7. Surface morphology of PVC-L-Cu under SEM after $300 \mathrm{~h}$ exposure to UV light (a) $20 \mu \mathrm{m}$; (b) $10 \mu \mathrm{m}$ and (c) $5 \mu \mathrm{m}$ scale.

In-depth SEM images analyzing showing a honeycomb-like to rounded conformations due to the coordination crosslinking between PVC chains may be attributed to the taped solvent's evaporation process (THF) within the polymer matrix in the preparation step [33]. The presence of $\mathrm{Cu}$ within the polymer matrix may support such conformations as the system tend to be in the highest stable form. The porous nature of the polymer film increases the surface area derived by solvent nature and polymer concentration. The elemental composition of the final compound (PVC-L-Cu) was analyzed via the EDX technique. EDX chart shows some significant peaks attributed to the corresponding element, as illustrated in figure 8.

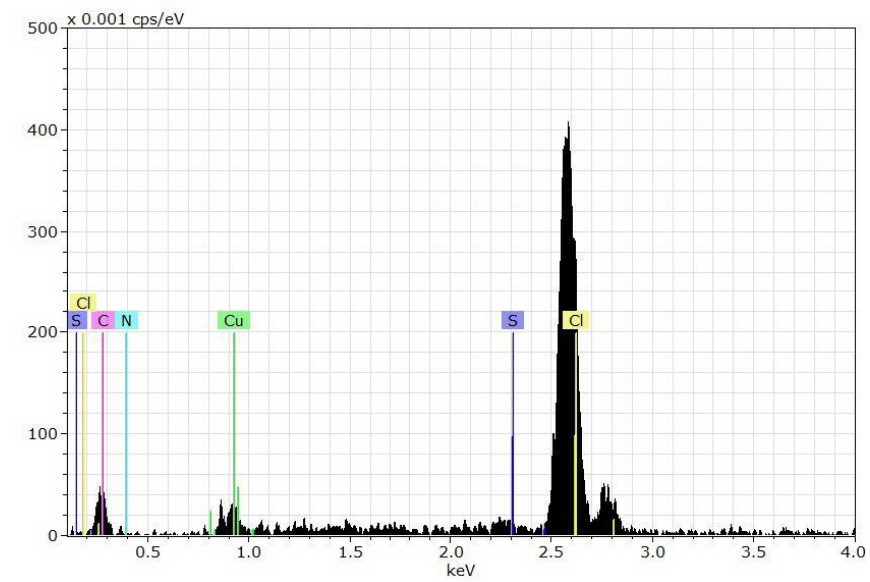

Figure 8. EDX graph for elemental composition of PVC-L-Cu film.

\section{Conclusions}

A simple method was applied to modify PVC with a newly synthesized Schiff base containing 1,2,4-triazole moiety. FTIR spectroscopy was used to monitor the degradation of 
PVC via investigating the changes in carbonyl index. Also, weight loss was also used to examine the changes in PVC after UV exposure. The results showed that the modified PVC is much stable than the pristine PVC sample. SEM microscopy showed a honeycomb-like to rounded conformations. Metal containing polymer was the most stable compound under UV irradiation.

\section{Funding}

This research received no external funding.

\section{Acknowledgments}

The authors would like to extend their appreciation to Al-Nahrain University for continued support.

\section{Conflicts of Interest}

The authors declare no conflict of interest.

\section{References}

1. Al-Salem, S.M.; Antelava, A.; Constantinou, A.; Manos, G. Dutta, A. A review on thermal and catalytic pyrolysis of plastic solid waste (PSW). J. Environ. Manage. 2017, 197, 177-198, https://doi.org/10.1016/j.jenvman.2017.03.084.

2. Li, J.; Lu, H.; Guo, J.; Xu, Z.; Zhou, Y. Recycle Technology for Recovering Resources and Products from Waste Printed Circuit Boards. Environ. Sci. Technol. 2007, 41, 1995-2000, https://doi.org/10.1021/es0618245.

3. Ghosh, S.; Alghunaim, A.S.; Al-mashhadani, M.H.; Krompiec, M.P.; Hallett, M.; Perepichka, I.F. 4,5Diazafluorene co-oligomers as electron deficient light-emitting materials and selective fluorescence sensors for mercury (II) cations. J. Mater. Chem. C. 2018, 6, 3762-3773, https://doi.org/10.1039/C7TC05051H.

4. Pratap Rao, D. A review on versatile applications of novel Schiff bases and their metal complexes. Letters in Applied NanoBioScience 2019, 8, 675-681, https://doi.org/10.33263/LIANBS84.675681.

5. Ahmed, W.A.; Al-Mashhadani, M.H.; Abdallh, M.; Hussain, Z.; Yousif, E. Eco-friendly green corrosion inhibitors in overview. Research Journal in Advanced Sciences 2020, 1, 7-16.

6. Ahmed, A.A.; Al-mashhadani, M.H.; Hussain, Z.; Mohammed, S.A.; Yusop, R.M.; Yousif, E. Inhibition of Corrosion: Mechanisms and Classifications an Overview. JOPS 2020, 25, 1-9, https://doi.org/10.29350/qjps.2020.25.2.1072.

7. Ahmed, A.A.; Al-mashhadani, M.H.; Hashim, H.; Ahmed, D.S.; Yousif, E. Morphological, Color Impact and Spectroscopic Studies of New Schiff Base Derived From 1,2,4-Triazole Ring. Prog. Color Colorants Coat 2021, 14, 27-34, https://doi.org/10.30509/pccc.2021.81664.

8. Correa, C.A.; de Santi, C.R.; Leclerc, A. Green-PVC with full recycled industrial waste and renewably sourced content. J. Clean. Prod. 2019, 229, 1397-1411, https://doi.org/10.1016/j.jclepro.2019.04.383.

9. Suresh, S.S.; Mohanty, S.; Nayak, S.K. Synthesis and application of functionalised acrylonitrile-butadiene rubber for enhancing recyclability of poly(vinylchloride) (PVC) and poly(methylmethacrylate) (PMMA) in recycled blends. Clean Techn Environ Policy. 2018, 20, 969-979, https://doi.org/10.1007/s10098-0181514-6.

10. Khalaf, M.; Fadhil, Z.; Al-Mashhadani, M.H.; Abdallh, M.; Bufaroosha, M.; Majeed, A.; Salih, N.; Yousif, E. PVC Films Performance Stabilized By Dibutyltin (IV) Complex For Sustainable Environment. Journal of Physics: Conference Series 2020, 1664, https://doi.org/10.1088/1742-6596/1664/1/012072.

11. Mohammed, S.A.; Najim, L.H.; Al-Mashhadani, M.H.; Ismael, M.; Hamad, B.A.; Noaman, R.; Ibraheem, H.; Ahmed, D.S.; Yousif, E. Morphological and Photodecomposition Rate Constant Study of PVC Films Doped with Sulfadiazine Tin (IV) Complexes. Science Letters 2020, 14, 88-96.

12. Tanu, S.; Sanjeev, A.; Shyam, K.; Mittal, V.; Kalsi, P.; Manchanda, V. Effect of gamma irradiation on the optical properties of CR-39 polymer. Journal of Materials Science 2007, 42, 1127-1130, https://doi.org/10.1007/s10853-006-0516-7.

13. Learner, T. Modern Paints Uncovered. The Getty Conservation Institute, Los Angeles, 2008.

14. Jablonski, E.; Learner, T.; Hayes, J.; Golden, M. The Conservation of Acrylic Emulsion Paintings: a Literature Review. Tate Papers, Tate's Online Research Journal, 2004. 
15. Bufaroosha, M.; Salih, N.; Hadi, A. G.; Ahmed, D.S.; Al-mashhadani, M.H.; Yousif, E. The Effect of UV Aging on the Structure of PVC in the Presence of Organotin (IV) Compounds. Al-Nahrain Journal of Science 2020, 23, 57-61, https://doi.org/10.22401/ANJS.23.1.08.

16. Yousif, E.; Abdalla, M.; Ahmed, A.; Salimon, J.; Salih, N. Photochemical stability and photostabilizing efficiency of poly(methyl methacrylate) based on 2-thioacetic acid-5-phenyl-1,3,4-oxadiazole complexes. Arab. J. Chem. 2016, 9, S595-S601.

17. Dintcheva, N.T.; La Mantia, F.P. Durability of a starch-based biodegradable polymer. Polymer Degradation and Stability 2007, 92, 630-634, https://doi.org/10.1016/j.polymdegradstab.2007.01.003.

18. Coelho, C.; Hennous, M.; Verney, V.; Leroux, F. Functionalisation of polybutylene succinate nanocomposites: from structure to reinforcement of UV-absorbing and mechanical properties. Rsc Advances 2012, 2, 5430-5438, https://doi.org/10.1039/C2RA20579C.

19. Ahmed, A.A.; Ahmed, D.S.; El-Hiti, G.A.; Alotaibi, M.H.; Hashim, H.; Yousif E. SEM morphological analysis of irradiated polystyrene film doped by a Schiff base containing a 1,2,4-triazole ring system. Applied Petrochemical Research 2019, 9, 169-177, https://doi.org/10.1007/s13203-019-00235-6.

20. Smith, S.H.; Taylor, L.T. Extraction of various additives from polystyrene and their subsequent analysis. Chromatographia 2002, 56, 165-169, https://doi.org/10.1007/BF02493206.

21. Tunali-Akbay, T.; Kahraman M.V.; Oktay, B.; İpekci, H.; Kayaman-Apohan, N. Bioactivated poly (vinyl alcohol) /poly(acrylic acid) based nanofiber for high-performance membrane techniques. Letters in Applied NanoBioScience 2020, 9, 819-823, https://doi.org/10.33263/LIANBS91.819823.

22. Yousif, E.; Haddad, R.; El-Hiti, G.A.; Yusop, R.M. Spectroscopic and photochemical stability of polystyrene films in the presence of metal complexes. J. Taibah Univ. Sci 2017, 11, 997-1007, https://doi.org/10.1016/j.jtusci.2017.03.002.

23. Rabie, S.T.; Ahmed, A.E.; Sabaa, M.W.; Abd El-Ghaffar, M.A. Maleic diamides as photostabilizers for polystyrene. J. Ind. Eng. Chem 2013, 19, 1869-1878, https://doi.org/10.1016/j.jiec.2013.02.033.

24. Watheq, B.; Yousif, E.; Al-Mashhadani, M.H.; Mohammed, A.; Ahmed, D.S.; Kadhom, M.; Jawad, A.H. A Surface Morphological Study, Poly(Vinyl Chloride) Photo-Stabilizers Utilizing Ibuprofen Tin Complexes against Ultraviolet Radiation. Surfaces 2020, 3, 579-593, https://doi.org/10.3390/surfaces3040039.

25. Karakas, A.; Elmali, A.; Ünver, H.; Svoboda, I. Nonlinear optical properties of some derivatives of salicylaldimine-based ligands. J. Mol. Struct $2004, \quad$ 702, https://doi.org/10.1016/j.molstruc.2004.06.017.

26. Eftekhari, S.; Foroughifar, N.; Khajeh-Amiri, A.; Hallajian, S. Synthesis and characterization of polymeric nanocomposites based on poly-melamine-paraformaldehyde and superparamagnetic silicon dioxide loaded Iron(III) oxide core-shell composite magnetic nanoparticles. Letters in Applied NanoBioScience 2020, 9 , 914-918, https://doi.org/10.33263/LIANBS91.914918.

27. Pandeya, S.N.; Sriram, D.; Nath, G.; DeClercq, E. Synthesis, antibacterial, antifungal and anti-HIV activities of Schiff and Mannich bases derived from isatin derivatives and N-[4-(40-chlorophenyl)thiazol-2-yl] thiosemicarbazide. Eur. J. Pharm. Sci 1999, 9, 25-31, https://doi.org/10.1016/S0928-0987(99)00038-X.

28. Shivarama, B.; Veerendra, B.; Shivananda, M.K.; Poojary, B. Synthesis characterization and anticancer activity studies on some Mannich bases derived from 1,2,4-triazoles. Eur. J. Med. Chem 2003, 38, 759-767, https://doi.org/10.1016/S0223-5234(03)00128-4.

29. Pouretedal, H. R.; Damiri, S.; Karami, Z. Increasing of photostability of HNS explosive in the presence of UV photostabilizers. Defence Technology 2020, in press, https://doi.org/10.1016/j.dt.2020.02.001.

30. Nakatani, H.; Kyan, T.; Urakawa, Y. Novel Recycling System of Polystyrene Water Debris with Polymer Photocatalyst and Thermal Treatment. J Polym Environ 2020, 28, 3279-3288, https://doi.org/10.1007/s10924-020-01976-5.

31. Nikafshara, S.; McCracken, J.; Dunnec, K.; Nejad, M. Improving UV-Stability of epoxy coating using encapsulated halloysite nanotubes with organic UV-Stabilizers and lignin. Progress in Organic Coatings 2021, 151, https://doi.org/10.1016/j.porgcoat.2020.105843.

32. Krishnan, T.; Salida Wan Mansor, W. Photocatalytic Degradation of Dyes by TiO2 Process in Batch Photoreactor. Letters in Applied NanoBioScience 2020, 9, 1502-1512, https://doi.org/10.33263/LIANBS94.15021512.

33. Xiao, L.; Zhao, Y.; Jin, B.; Zhang, Q.; Chai Z.; Peng, R. Synthesis of novel ultraviolet stabilizers based on [60]fullerene and their effects on photo-oxidative degradation of polystyrene. Fullerenes, Nanotubes and Carbon Nanostructures 2020, 28, 465-473, https://doi.org/10.1080/1536383X.2019.1703695. 